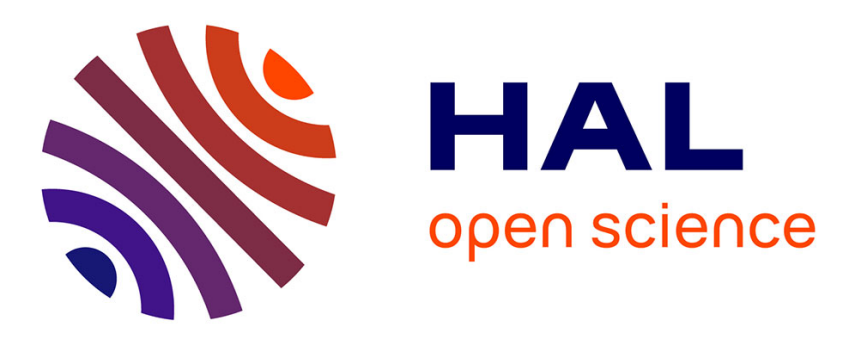

\title{
Effect of polysaccharides on the hydration of cement paste at early ages
}

Arnaud Peschard, Alexandre Govin, Philippe Grosseau, Bernard Guilhot, René Guyonnet

\section{- To cite this version:}

Arnaud Peschard, Alexandre Govin, Philippe Grosseau, Bernard Guilhot, René Guyonnet. Effect of polysaccharides on the hydration of cement paste at early ages. Cement and Concrete Research, 2004, 34(11), pp.2153. hal-00124310

\section{HAL Id: hal-00124310 https://hal.science/hal-00124310}

Submitted on 12 Jan 2007

HAL is a multi-disciplinary open access archive for the deposit and dissemination of scientific research documents, whether they are published or not. The documents may come from teaching and research institutions in France or abroad, or from public or private research centers.
L'archive ouverte pluridisciplinaire HAL, est destinée au dépôt et à la diffusion de documents scientifiques de niveau recherche, publiés ou non, émanant des établissements d'enseignement et de recherche français ou étrangers, des laboratoires publics ou privés. 


\title{
Effect of polysaccharides on the hydration of cement paste at early
}

\section{ages}

\author{
A. Peschard, A. Govin ", P. Grosseau, B. Guilhot, R. Guyonnet
}

Ecole Nationale Supérieure des Mines de Saint Etienne, LPMG: process in granular system laboratory CNRS UMR 5148, Centre SPIN, Department of Materials Engineering (PC2M), 158 cours Fauriel 42023 Saint Etienne cedex, FRANCE

\footnotetext{
${ }^{\ominus}$ A.Peschard and A.Govin have contributed equally to this work

* Corresponding author. Tel: 33 (0)4 774202 74; fax: 33 (0)4 77499694

E-mail address: govin@emse.fr
} 


\begin{abstract}
This work deals with the relative efficiency of polysaccharides and their influence on cement hydration. Several parameters such as the structure, concentration, average molecular weight, and soluble fraction value of polysaccharides were examined. Cement hydration was monitored by isothermal calorimetry, thermogravimetry (TGA), and infra-red spectroscopy (FTIR). Results clearly show that retardation increases with higher polysaccharide-to-cement weight ratio $(\mathrm{P} / \mathrm{C})$. Low molecular weight starch showed enhanced retarding effect on the hydration of cement. The retardation effect of polysaccharides is also dependant on the composition of cement.
\end{abstract}

Keywords :. Hydration ; Polymers ; Polysaccharides ; Retardation ; Cement Paste

\title{
1. Introduction
}

Organic admixtures have been widely used in concrete and mortar for several decades, providing advanced specific properties needed during the construction. The European market of coatings is changing to the advantage of the remodelling market. Mortars for this application require a water retention value of at least 95\% to prevent water absorption. To obtain this value, polysaccharides which can be equally classified as water-reducers and setretarding agents, are frequently used. These admixtures can be either native bio-polymers (e.g. starch) or substituted polymers (e.g. cellulose ethers). Dewacker et al. [1] suggested that a blend of polysaccharides such as cellulose and starch was a good water retention agent. 
These admixtures are also set-retarding agents which improve workability duration and modify cement hydration. Yamamuro [2] showed that a polysaccharide derivative containing an ionic functional group and a hydrophobic group increases the viscosity of cement suspensions. In the Shotcrete process, Ghio et al. [3,4] showed that concretes formulated with polysaccharides are easier to pump and to spray at high shear rates than unadmixed concrete. Moreover, concrete is more cohesive and viscous at low shear rates. Tanaka et al. [5] patented an additive that contains at least one sulfated polysaccharide to improve fluidity and workability and that supplies higher final compressive strength. Hayakawa et al. [6,7] reported that cellulose ether improves binding between cement matrix and aggregates.

Previous investigations on physico-chemical aspects were restricted to the effect of monosaccharides or sugar acids on cement or single phase hydration [8-11]. Influence of such admixtures on Calcium aluminate phase $\left(\mathrm{C}_{3} \mathrm{~A}\right)$ was studied by Young [8] who showed that, interaction of sugars on $\mathrm{C}_{3} \mathrm{~A}$ prevents rapid formation of the cubic phase $\mathrm{C}_{3} \mathrm{AH}_{6}$ and promotes formation of the hexagonal phase $\mathrm{C}_{4} \mathrm{AH}_{13}$. Collepardi et al. $[9,10]$ found that addition of glucose, gluconate or lignosulfonate stabilizes ettringite in the $\mathrm{C}_{3} \mathrm{~A}$-gypsum system. It was also noted that glucose retards gypsum consumption and ettringite formation.

Many studies on the hydration of silicate phase in presence of admixtures were devoted to the determination of calcium hydroxide content. According to Milestone [11] the retarding effect is as follows: sugar acids $>$ sugars $>$ lignosulfonates. Scanning electron microscopic (SEM) examination showed that in presence of these admixtures, calcium silicate phase $\left(\mathrm{C}_{3} \mathrm{~S}\right)$ particles are covered by flaky calcium silicate hydrate $(\mathrm{CSH})$, instead of acicular hydrates [11]. 
Bensted et al. [15] investigated the effect of lignosulfonate on the hydration of cement and found that retardation is linked either to a preferential complexation with calcium and silicon or to an introduction of organic admixtures into a precipitated gel. This latter hypothesis postulates that the retarding effect would come from the formation of a less permeable gel coating around cement grains. However the mechanism of cement-admixture interaction is yet to be fully understood.

The present study was undertaken to determine the relative efficiencies of polysaccharides and to reveal the mechanism of interaction between cement particles and the admixture at the early stages of hydration.

\section{Experimental}

\subsection{Raw materials}

White Porland cement $\left(\mathrm{C}_{1}\right)$ : CPA CEM I 52.5, and grey cement $\left(\mathrm{C}_{2}\right)$ : PMES 42.5 were used in this study. The designation follows French standard NF P 15-301. Chemical composition and mineralogical phases of the two cement samples were calculated by the Bogue approximation [12], and these are listed in Table 1.

Five powder polysaccharides, a cellulose ether (CE), a starch ether (SE), a native starch (NS), a white dextrin (WD), and a yellow dextrin (YD) both prepared from NS, were tested. Properties of these polysaccharides are given in Table 2.

\subsection{Methods of investigation}


Isothermal microcalorimetry, TGA and FTIR spectrometry were used to monitor kinetics and mechanism of cement hydration.

Each experiment was conducted in triplicate. In each case, cement and polysaccharides were mixed for 2 periods of 2 minutes using a shaker-mixer (Wab, Turbula, Germany). Unless otherwise stated, polysaccharide to cement weight ratio (P/C) was equal to 0.5 (w/w).

Deionized water to cement ratio (W/C) was approximately 0.3 and was adjusted in order to have a constant workability. The W/C values of $C_{1}, C_{1}+C E, C_{1}+S E, C_{1}+N S, C_{1}+W D$, $\mathrm{C}_{1}+\mathrm{YD}, \mathrm{C}_{2}, \mathrm{C}_{2}+\mathrm{YD}$ were 0.282, 0.265, 0.342, 0.295, 0.295, 0.267, 0.215, 0.225 respectively. Cement pastes were obtained by using a mixer (Technotest, France) for one minute at low speed $(60 \mathrm{rpm})$ and four minutes at high speed $(120 \mathrm{rpm})$. Samples were stored in a water vapour saturated desiccator and under nitrogen atmosphere. Cement hydration was stopped by breaking and grinding hydrated samples and washing them with anhydrous ethanol. Samples were ground in an agate mortar until each particle diameter became lower than $100 \mu \mathrm{m}$. This step was reproduced at different lengths of time ranging from 1 to 24 hours.

Thermal analysis was performed on a TG-DSC 111 thermogravimetric apparatus (Setaram, France). All experiments were conducted from $20^{\circ} \mathrm{C}$ up to $800^{\circ} \mathrm{C}$ (heating rate of $10^{\circ} \mathrm{C} / \mathrm{min}$ ) under dynamic argon atmosphere on a approximately $25 \mathrm{mg}$ samples.

The amount of portlandite $\mathrm{CH}(\%)$ was obtained directly from TG curves by Eq.1

$$
\mathrm{CH}(\%)=\mathrm{WL}_{\mathrm{CH}}(\%) \times \frac{\mathrm{MW}_{\mathrm{CH}}}{\mathrm{MW}_{\mathrm{H}}}
$$

where $\mathrm{WL}_{\mathrm{CH}}(\%)$ corresponds to weight loss in percent occurring during $\mathrm{CH}$ dehydration, $\mathrm{MW}_{\mathrm{CH}}$ and $\mathrm{MW}_{\mathrm{H}}$ are molecular weights of portlandite and water respectively. 
Infra-red spectra were collected with a spectrometer (Biorad FTS 185 Digilab, USA) equipped with a Harrick scattering reflexion accessory. Analysis was conducted on hydrated samples diluted at 5\% in KBr. Spectra were converted by the Kubelka-Munk algorithm.

Admixtures can be classified in retarders or accelerators category using isothermal microcalorimetry [13]. It enables the hydration process to be monitored continuously. It was conducted on a C80 calorimeter (Setaram, France). Temperature of the calorimetric block was maintained at $25^{\circ} \mathrm{C}$ and the experiments were conducted on a $250 \mathrm{mg}$ sample at a W/C ratio of 0.4. Cement and water mixing was done outside the calorimeter according to the procedure described by Sauvat et al. [14] and Ramachandran et al. [15]. Consequently, only the exothermic hydration peak was encountered.

\section{Results and discussion}

\subsection{Hydration of $C_{1}$}

Investigations were first focused on $\mathrm{C}_{1}$ since this kind of cement is frequently used in coating formulas. The calorimetric curve of neat cement exhibits two separate exothermic peaks. According to Sauvat et al. [14] they correspond to $\mathrm{C}_{3} \mathrm{~A}$ and $\mathrm{C}_{3} \mathrm{~S}$ hydration peaks respectively whereas Bensted et al. [16] suggested the reverse order. Retarding ability of polysaccharides on cement hydration is obtained from curves of heat evolution rate. Three different times were defined as proposed by Sauvat et al. [14], $t_{1}, t_{2}, t_{3}$ which correspond to minimum flux time, second peak time and third peak time respectively. Heat released in 24 hours of hydration was calculated by curve integration from $t_{1}$ to $t_{24 h}$ (Table 3 ). Intensity and shape of the exothermic peaks are not significantly modified by CE and NS addition. Intensity of heat flow for cement formulated with SE is lower. The cement admixed with YD presents a 
larger wetting peak which induces a shift of the minimum heat flow to 10 hours. Moreover, the heat released during the first 24 hours of hydration is smaller. These results confirm previous studies regarding effects of set-retarding agents on cement hydration [14,15]. Ramachandran et al. [15] found that sucrose is an efficient retarder which extends induction period for several hours. Similar result was obtained with YD in the present study.

Previte et al. [17] suggested that alkali-stable and high molecular weight sugars are more efficient to retard hydration. It should be noted that oligomers used by these authors had a maximum chain length of 3 units. To extend this previous study, the present results focus on polysaccharides with a much higher degree of polymerization. Polysaccharides with a strong set- retarding ability i.e., SE and YD have a lower average molecular weight than CE and NS. A weak average molecular weight favors alkali-degradation of polysaccharides [18-19]. Several authors have shown that products from decomposition of sugar are more effective than native sugars $[15,20]$.

Differential Thermal Analysis (DTA) and TGA were used to study the effects of sugars and hydroxycarboxylic acids on hydration of different cement phases. As Bensted et al. [21] and Odler et al. [22] suggested, it is possible to assign the first two peaks at $120^{\circ} \mathrm{C}$ and $145^{\circ} \mathrm{C}$ to ettringite and gypsum decomposition respectively (Fig. 1a). Beyond 4 hours of hydration, decomposition peaks of CSH and ettringite overlap. It is also possible to monitor gypsum consumption until it completely disappears since no other phase interferes with it. Decomposition peak of $\mathrm{CH}$ occurs between $420^{\circ} \mathrm{C}$ and $460^{\circ} \mathrm{C}$.

The $\mathrm{C}_{1}+\mathrm{SE}$ formula revealed a smaller amount of ettringite and a smaller gypsum consumption than $\mathrm{C}_{1}$ (Fig. 1b). However the admixture YD accelerated gypsum consumption and ettringite formation (Fig. 1c) as compared with $\mathrm{C}_{1}$. It can be at the origin of the wetting peak broadening on the calorimetric curve. Between 4 and 8 hours of hydration, the ettringite 
phase seems to be stabilized and gypsum is no longer consumed for both formulas. Moreover, decomposition peak of portlandite is less intense for $C_{1}+S E$ and $C_{1}+Y D$. Further information is obtained by calculation of portlandite content as specified by Eq. 1. Portlandite formation depends strongly on the type of polysaccharide introduced in cement (Fig. 2). YD stops portlandite formation during 8 hours. Beyond this period the formation rate increases and finally portlandite content is very close to those of pure cement. Conversely, CE and NS have had no significant effect on gypsum consumption, on ettringite as well as on portlandite formation (Fig. 2).

A smaller amount of portlandite could be associated with a greater carbonation as proposed by Silva et al. [23] for cement admixed with ethylene/vinyl acetate copolymer. Weight losses occurring during decarbonation were compared. Carbonation does not significantly increase upon polysaccharide incorporation. Thus, at a given time the presence of admixtures YD and SE induces a smaller content of portlandite.

$\mathrm{CSH}$ formation was monitored by infra-red spectroscopy since monitoring by thermal analysis at early ages is not possible. CSH is usually observed by a gradual shift of band centered at $925 \mathrm{~cm}^{-1}$ to $970 \mathrm{~cm}^{-1}$, which is assigned to the asymmetrical $\mathrm{SiO}_{4}$ stretching frequency [21]. It indicates polymerization of silicate units $\mathrm{SiO}_{4}{ }^{4-}$ with formation of $\mathrm{CSH}$ phase [24]. CSH has already been formed for $\mathrm{C}_{1}$ and $\mathrm{C}_{1}+\mathrm{CE}$ at 8 hours of hydration (Fig. 3). On the contrary, $\mathrm{C}_{1}+\mathrm{SE}$ and $\mathrm{C}_{1}+\mathrm{YD}$ revealed no shift attributed to $\mathrm{CSH}$ formation.

Results obtained from these studies are consistent. CE has no significant effect on hydrate formation. YD extends induction period, favours ettringite formation at very early ages and retards $\mathrm{CSH}$ and $\mathrm{CH}$ formation. SE slows down ettringite formation and gypsum consumption and also delays considerably $\mathrm{CSH}$ and $\mathrm{CH}$ formation. 


\subsection{Influence of SE and YD concentration on cement hydration}

Results obtained by isothermal microcalorimetry for an increasing amount of polysaccharides are listed in Table 4 . It shows that $t_{1}$ and $t_{2}$ are not significantly modified by an increase of SE concentration. Time $t_{3}$ is not defined for SE concentration over $0.5 \%$. As YD concentration rises, $t_{1}$ and $t_{2}$ are shifted to later times. In both formulas, evolution of heat released is inversely proportional to concentration. Results of $\mathrm{C}_{1}+\mathrm{YD}$ are consistent with those of Ramachandran et al. [15] who proposed a linear relation between concentration of retarders and duration of induction period.

\subsection{Study on the admixture YD}

\subsubsection{Influence of cement composition on retarding ability of YD}

In order to determine the effect of cement composition and especially $\mathrm{C}_{3} \mathrm{~A}$ content on set-retarding ability of polysaccharides, cement $\mathrm{C}_{2}$ was studied. For this experiment admixture YD was used, as it has a strong retarding effect on cement hydration. As illustrated in

(Fig. 4a), gypsum was totally consumed for pure $C_{2}$ after 16 hours of hydration. Introduction of YD revealed a decomposition peak at $145^{\circ} \mathrm{C}$ attributed to gypsum up to 24 hours (Fig. 4b).

Portlandite formation rate is higher for $C_{1}$ than $C_{2}$ (Fig. 5). It can be associated with a higher $\mathrm{C}_{3} \mathrm{~S}$ content for $\mathrm{C}_{1}$. $\mathrm{C}_{3} \mathrm{~A}$ amount seems to be an important parameter since $0.5 \%$ of $\mathrm{YD}$ totally inhibits portlandite formation up to 48 hours. Present results are similar to those of Singh [24]. Monosi et al. [26] found that lignosulfonate totally stops $\mathrm{C}_{3} \mathrm{~S}$ hydration up to two weeks without $\mathrm{C}_{3} \mathrm{~A}$. The inhibiting effect lasts only one day with $\mathrm{C}_{3} \mathrm{~A}$. It reveals the importance of $\mathrm{C}_{3} \mathrm{~A}$ content in cement which acts as a sink for retarders [15]. 
$\mathrm{C}_{2}$ hydrated with $0.5 \%$ YD suggests an excess of admixture with respect to cement. $\mathrm{P} / \mathrm{C}_{3} \mathrm{~A}$ ratio for this formula is 0.2 instead of 0.045 for $\mathrm{C}_{1}+0.5 \% \mathrm{YD}$. In order to verify the fact that an excess of $\mathrm{YD}$ with respect to $\mathrm{C}_{2}$ was introduced, an experiment on $\mathrm{C}_{1}+3 \%$ YD was carried out (ratio $\mathrm{P} / \mathrm{C}_{3} \mathrm{~A}$ equal to 0.25 ). Results obtained with this formula are similar to $\mathrm{C}_{2}+0.5 \% \mathrm{YD}$, i.e., portlandite formation was completely inhibited.

\subsubsection{Influence of dextrinization on set retarding ability of starch compounds}

WD and YD were obtained from NS by dextrinization which is a combination of an acid and a thermal treatment. It allows starch solubilization by a decrease of average molecular weight. Soluble fraction value increases with degree of conversion of starch to dextrin (Table 2). Thermal analysis is performed on $\mathrm{C}_{1}$ with $0.5 \%$ of admixture. YD delays portlandite formation whereas NS and WD have no effect (Fig. 6).

Average molecular weights and soluble fraction of starch derivatives are given in Table 2. At a given P/C ratio, YD concentration in liquid phase is higher than WD and NS concentration. Portlandite rate formation is more dependent on soluble fraction than on molecular weight of compounds. Dextrinization of NS is a predominant parameter on the retarding ability of starch derivatives.

\section{Conclusions}

Results obtained by thermal analysis show that the introduction of a small amount of polysaccharide ( $0.5 \%$ by weight of cement) induces a strong modification of cement 
hydration. Retarding ability is dependent on polysaccharide variety and is as follows: NS < $\mathrm{WD}<\mathrm{CE}<\mathrm{YD}<\mathrm{SE}$.

A mechanism which describes cement-polysaccharide interaction is difficult to establish. The first step of $\mathrm{C}_{3} \mathrm{~A}$ hydration leading to ettringite is accelerated by $\mathrm{YD}$ and retarded by SE. These polysaccharides then stabilize ettringite and gypsum content. This observation will induce a delay in conversion of ettringite to monosulfoaluminate phase. From these results, the action of polysaccharides on $\mathrm{C}_{3} \mathrm{~A}$ hydration seems more restricted to growth of hydrates than to nucleation. Consequently the origin of retardation could be linked to an adsorption of admixtures on the first hydrates forming a less permeable coating. As far as silicate hydration is concerned SE and YD (most effective polysaccharides) slow down and delay formation of both CSH and portlandite respectively.

Polysaccharide retarding effect depends on cement composition. $\mathrm{C}_{3} \mathrm{~A}$ content might be considered as a key parameter. Extent of retardation is higher for cement with low $\mathrm{C}_{3} \mathrm{~A}$ content which is in accordance with authors [15,25-26]. The retarding effect depends also on the chemical structure of admixtures. With respect to starch compounds, YD with a higher soluble fraction than NS and WD is more effective to retard cement hydration. A study with polysaccharides which have only one variable parameter, like degree of polymerization or degree of substitution, would produce valuable results in terms of admixture selection and properties prediction. Experiments on pure cement phase would provide useful information. It could be a first step to model pure phase hydration in presence of polysaccharide.

\section{Acknowledgements}


The authors acknowledge the financial support of Weber \& Broutin company (Servas, France) and Rhône-Alpes Region. The authors are grateful to J.F. Halet for his assistance. 


\section{References}

[1] D.R. Dewacker, B. Mcad, Cement mortar systems using blends of polysaccharides and cold-water-soluble unmodified starches, US Patent, 5, 575, 840 (1996).

[2] H. Yamamuro, Property of new polysaccharide derivative as a viscosity agent for self compacting concrete, First International Rilem symposium on self compacting concrete, Stockholm, Sweden (1999) 449-459.

[3] V.A. Ghio, P.J.M. Monteiro, The effects of polysaccharide gum additives on the shotcrete process, ACI Mater. J. 95 (2) (1998) 152-157.

[4] V.A. Ghio, P.J.M. Monteiro, L.A. Demsetz, The rheology of fresh cement paste containing polysaccharide gums, Cem. Concr. Res. 24 (2) (1994) 243-249.

[5] Y. Tanaka, T. Uryu, M. Yaguchi, Cement compositions containing a sulfated polysaccharide and method, US Patent, 5, 573, 589, (1996).

[6] K. Hayakawa, T. Soshiroda, An experimental study on the concrete containing cellulose ether, Transportation of Japan Concrete Institute 7 (1985) 17-24.

[7] K. Hayakawa, T. Soshiroda, Effects of cellulose ether on bond between matrix and aggregate in concrete, Adhesion between polymers and concrete proceedings (1986) 22-31

[8] J.F. Young, The influence of sugars on the hydration of tricalcium aluminate. Proceedings of the Fifth International Symposium on the Chemistry of Cement, Tokyo (1968) 256-267. 
[9] M. Collepardi, S. Monosi, G. Moriconi, M. Pauri, Influence of gluconate, lignosulfonate or glucose on the $\mathrm{C}_{3} \mathrm{~A}$ hydration in the presence of gypsum with or without lime, Cem. Concr. Res. 14 (1984) 105-112.

[10] M. Collepardi, S. Monosi, G. Moriconi, M. Pauri, Influence of gluconate, lignosulfonate, and glucose admixtures on the hydration of tetracalcium aluminoferrite in the presence of gypsum with or without calcium hydroxide, J. Am. Ceram. Soc. 68 (5) (1985) c126-c128.

[11] N.B. Milestone, Hydration of tricalcium silicate in the presence of lignosulfonates, glucose and sodium gluconate, J. Am. Ceram. Soc. 62 (7-8) (1979) 321-324.

[12] H.F.W Taylor, Cement Chemistry, Academic Press, New York, 1990, pp 62-63

[13] C.R. Wilding, A. Walter, D.D. Double, A classification of inorganic and organic admixtures by conduction calorimetry, Cem. Concr. Res.14 (1984) 185-194.

[14] N. Sauvat, R. Sell, E. Mougel, A. Zoulalian, A study of ordinary Portland cement hydration with wood by isothermal calorimetry, Holzforschung 53 (1) (1999) 104-108.

[15] V.S. Ramachandran, M.S. Lowery, Conduction calorimetric investigation of the effects of retarders on the hydration of Portland cement, Thermochim. Acta 195 (1992) 373-387.

[16] J. Bensted, Some applications of conduction calorimetry to cement hydration, Adv. Cem. Res 1 (1) (1987) 35-44. 
[17] R.W. Previte, Some insights on the mechanism of saccharide set retardation of Portland cement, Cem. Concr. Res 1 (1971) 301-316.

[18] R.L. Whistler, J.N. Bemiller, Alkaline degradation of polysaccharides, Advances in Carbohydrate Chemistry and Biochemistry 13 (1958) 289-329.

[19] C.J. Knill, J.F. Kennedy, Degradation of cellulose under alkaline conditions, Carbohydr. Polym. 51 (3) (2003) 281-300.

[20] G.M. Bruere, Set-retarding effects of sugars in Portland cement pastes, Nature 212 (1966) 502-503.

[21] J. Bensted, S.P. Varma, Some applications of infrared and raman spectroscopy in cement chemistry, Part 3-Hydration of portland cement and its constituents, Cem. Technol. (September/October 1974) 440-450.

[22] I. Odler, S. Abdul-Maula, Possibilities of quantitative determination of the Aft(ettringite) and Afm-(monosulphate) phases in hydrated cement pastes, Cem. Concr. Res 14 (1984) 133-141.

[23] D.A. Silva, H.R. Roman, P.J.P. Gleize, Evidences of chemical interaction between EVA and hydrating Portland cement, Cem. Concr. Res 32 (2002) 1383-1390.

[24] M.Y.A. Mollah, W. Yu, R. Schennach, D.L. Cocke, A Fourier transform infrared spectroscopic investigation of the early hydration of Portland cement and the influence of 
sodium lignosulfonate, Cem. Concr. Res 30 (2000) 267-273.

[25] N.B. Singh, Effect of gluconates on the hydration of cement, Cem. Concr. Res 6 (1976) 455-460.

[26] S. Monosi, G. Moriconi, M. Collepardi, Combined effect of lignosulfonate and carbonate on pure Portland clinker compounds hydration. III. Hydration of tricalcium silicate alone and in the presence of tricalcium aluminate, Cem. Concr. Res. 12 (1982) 425-435. 
Table 1

\begin{tabular}{|c|c|c|}
\hline Chemical composition & $\mathrm{C}_{1}$ & $\mathrm{C}_{2}$ \\
\hline $\mathrm{SiO}_{2}$ & 22.2 & 21.9 \\
\hline $\mathrm{TiO}_{2}$ & 0.2 & 0.4 \\
\hline $\mathrm{Al}_{2} \mathrm{O}_{3}$ & 4.4 & 3.8 \\
\hline $\mathrm{Fe}_{2} \mathrm{O}_{3}$ & 0.3 & 4.3 \\
\hline $\mathrm{CaO}$ & 67.2 & 62.8 \\
\hline $\mathrm{MnO}$ & 0.01 & 0.04 \\
\hline $\mathrm{MgO}$ & 0.5 & 2.2 \\
\hline $\mathrm{Na}_{2} \mathrm{O}$ & 0.4 & 0.4 \\
\hline $\mathrm{K}_{2} \mathrm{O}$ & 0.05 & 0.39 \\
\hline $\mathrm{P}_{2} \mathrm{O}_{5}$ & 0.11 & 0.26 \\
\hline $\mathrm{SO}_{3}$ & 3 & 2.6 \\
\hline Bogue approximation & $\mathrm{C}_{1}$ & $\mathrm{C}_{2}$ \\
\hline $\mathrm{C}_{3} \mathrm{~S}$ & 66 & 51 \\
\hline $\mathrm{C}_{2} \mathrm{~S}$ & 14 & 24 \\
\hline $\mathrm{C}_{3} \mathrm{~A}$ & 11 & 2.6 \\
\hline $\mathrm{C}_{4} \mathrm{AF}$ & 1 & 13.2 \\
\hline
\end{tabular}


Table 1 Chemical composition of cement and potential phases as determined by Bogue approximation.

A.Peschard, A.Govin ${ }^{*}$, P.Grosseau, B.Guilhot, R.Guyonnet 
Table 2

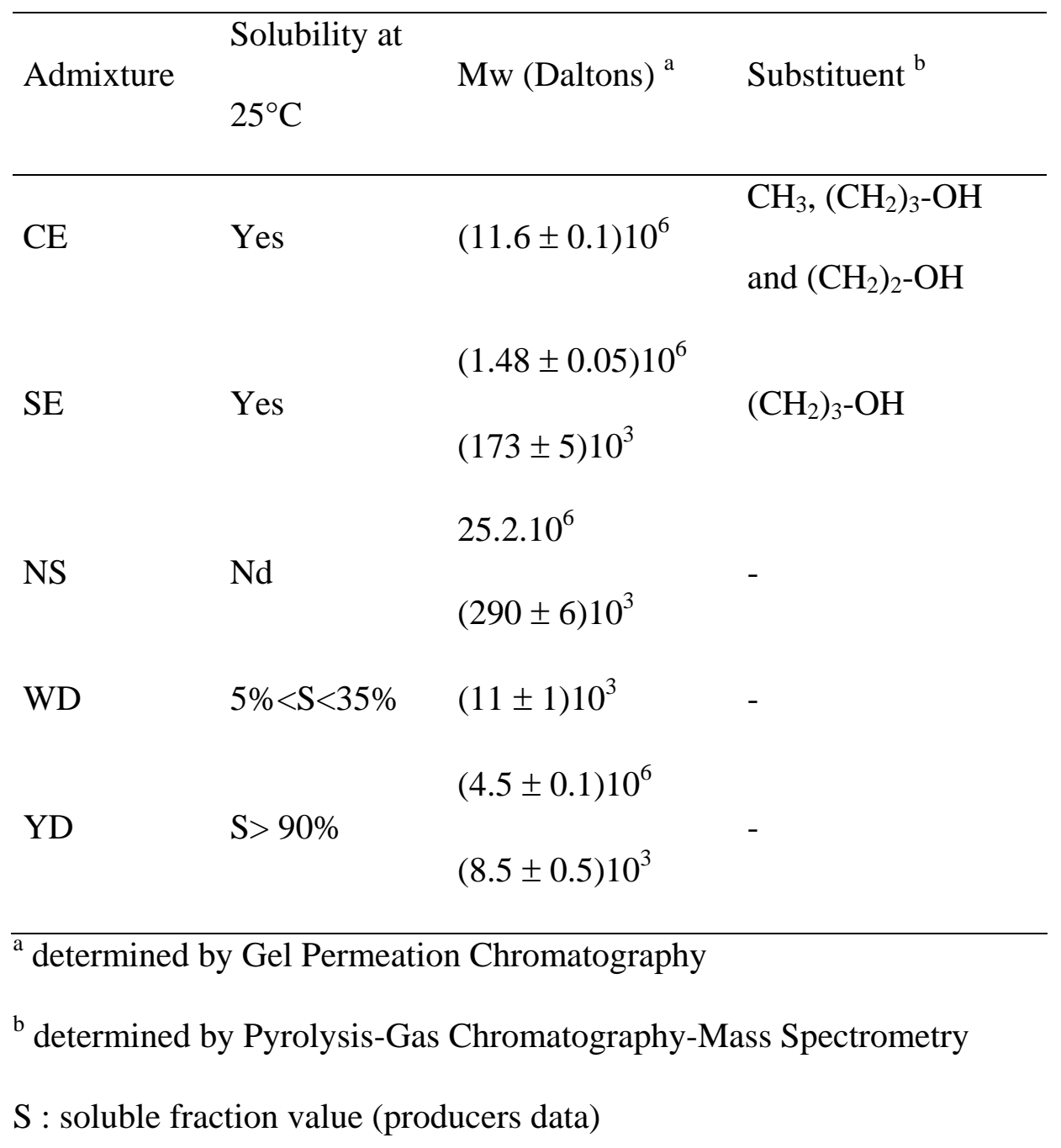


Table 2 Properties of polysaccharides.

A.Peschard, A.Govin, P.Grosseau, B.Guilhot, R.Guyonnet 
Table 3

\begin{tabular}{ccccc}
\hline Formula & $\mathrm{t}_{1}$ (hours) & $\mathrm{t}_{2}$ (hours) & $\mathrm{t}_{3}$ (hours) & $\mathrm{Q}_{24 \mathrm{~h}}(\mathrm{~J} / \mathrm{g})$ \\
\hline $\mathrm{C}_{1}$ & $2.4 \pm 0.3$ & $7.2 \pm 0.3$ & $11.2 \pm 0.6$ & $99 \pm 5$ \\
$\mathrm{C}_{1}+\mathrm{CE}$ & $3.5 \pm 0.5$ & $9.5 \pm 0.7$ & $13.5 \pm 0.7$ & $97 \pm 5$ \\
$\mathrm{C}_{1}+\mathrm{SE}$ & $2.2 \pm 1.5$ & $8.2 \pm 2.1$ & $14.5 \pm 4.1$ & $60 \pm 8$ \\
$\mathrm{C}_{1}+\mathrm{NS}$ & $2.9 \pm 0.2$ & $7.7 \pm 0.1$ & $11.4 \pm 0.1$ & $94 \pm 7$ \\
$\mathrm{C}_{1}+\mathrm{YD}$ & $7.9 \pm 0.4$ & $18.2 \pm 1.1$ & - & $9 \pm 1$ \\
\hline
\end{tabular}


Table 3 Times and heat released in 24 hours as a function of polysaccharide added.

A.Peschard, A.Govin, P.Grosseau, B.Guilhot, R.Guyonnet 
Fig 1a

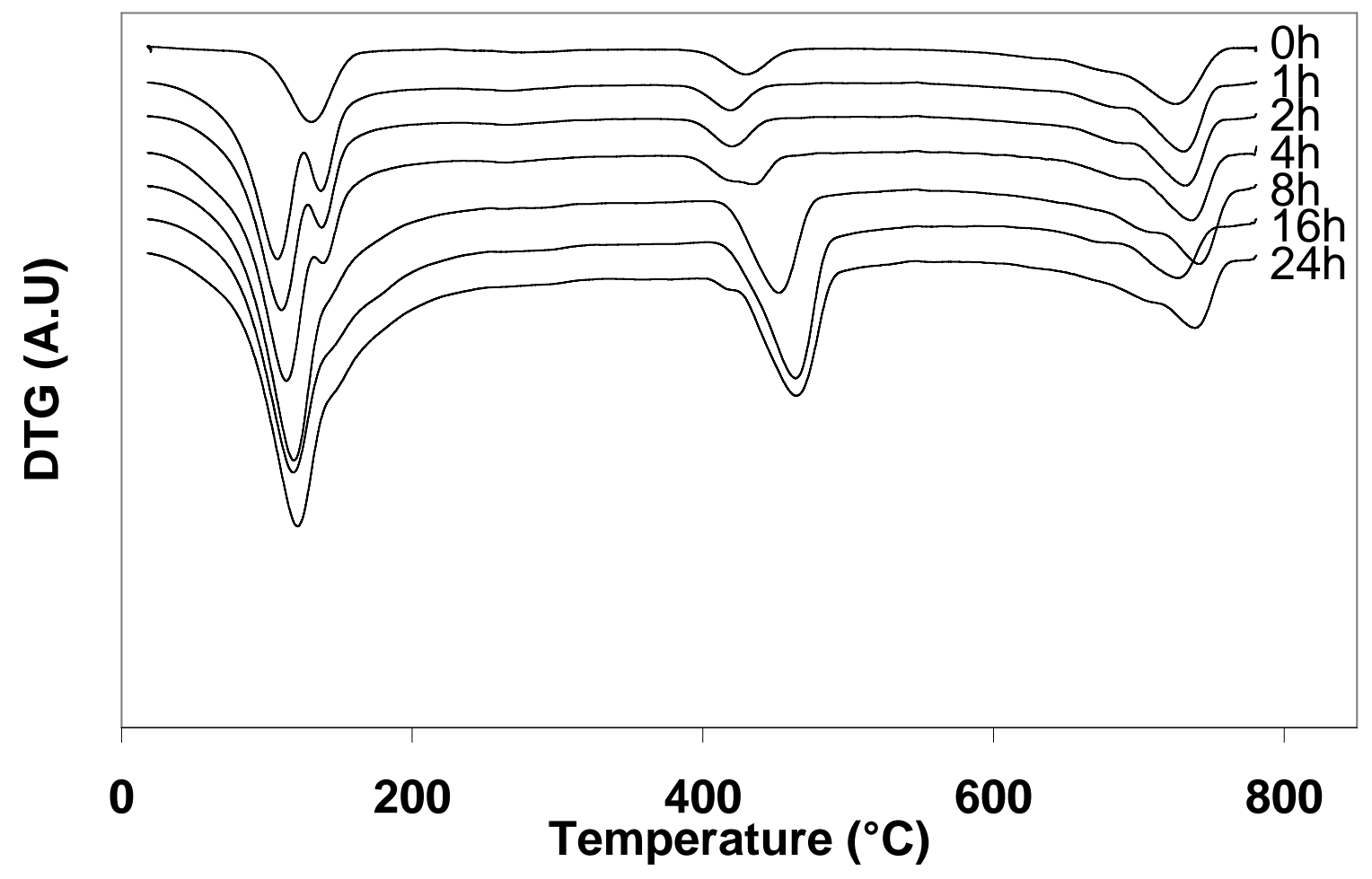


Fig 1a DTG curves of $\mathrm{C}_{1}$

A.Peschard, A.Govin, P.Grosseau, B.Guilhot, R.Guyonnet 
Fig 1b

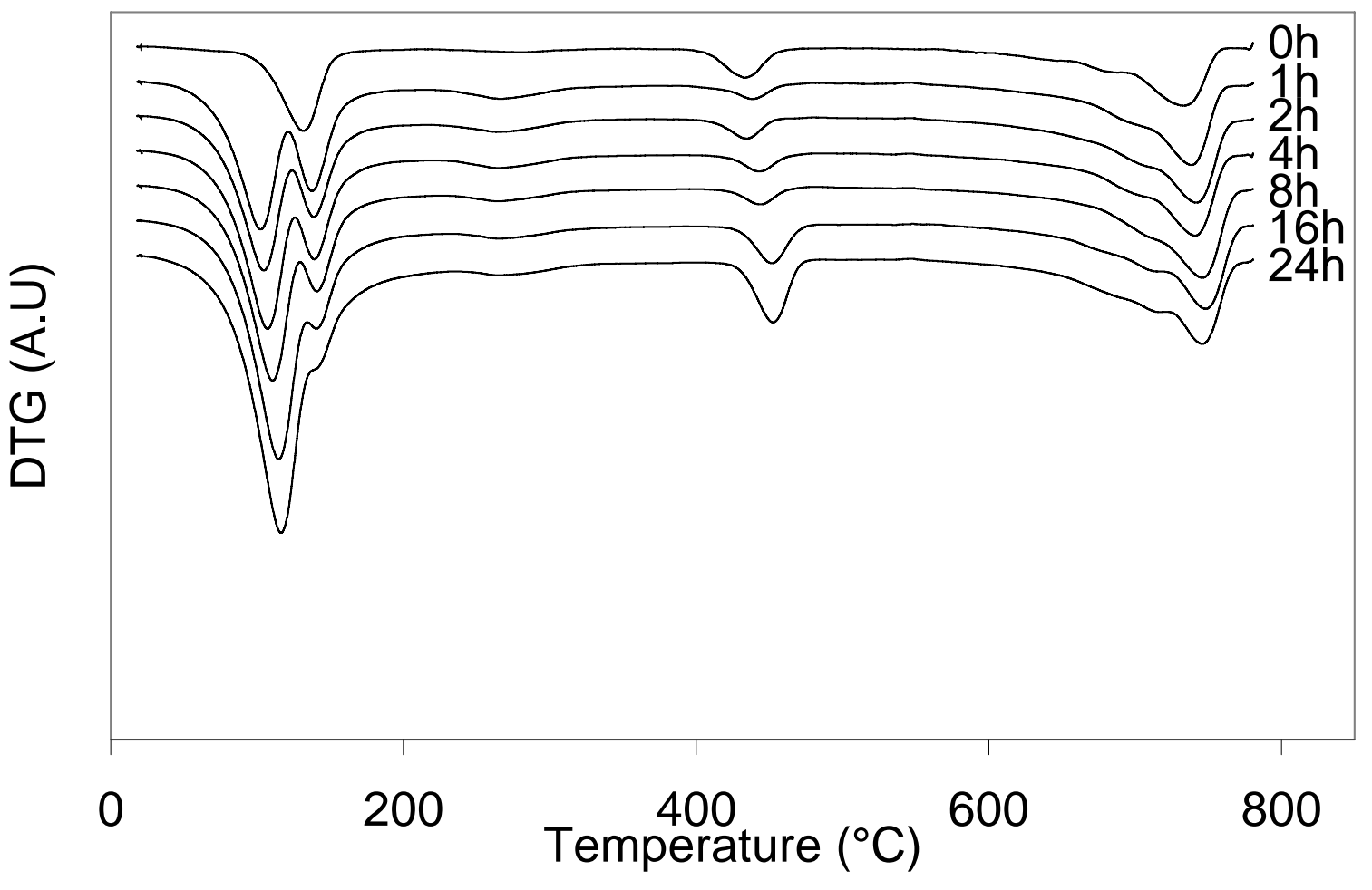


Fig 1b DTG curves of $\mathrm{C}_{1}+\mathrm{SE}$

A.Peschard, A.Govin, P.Grosseau, B.Guilhot, R.Guyonnet 
Fig 1c

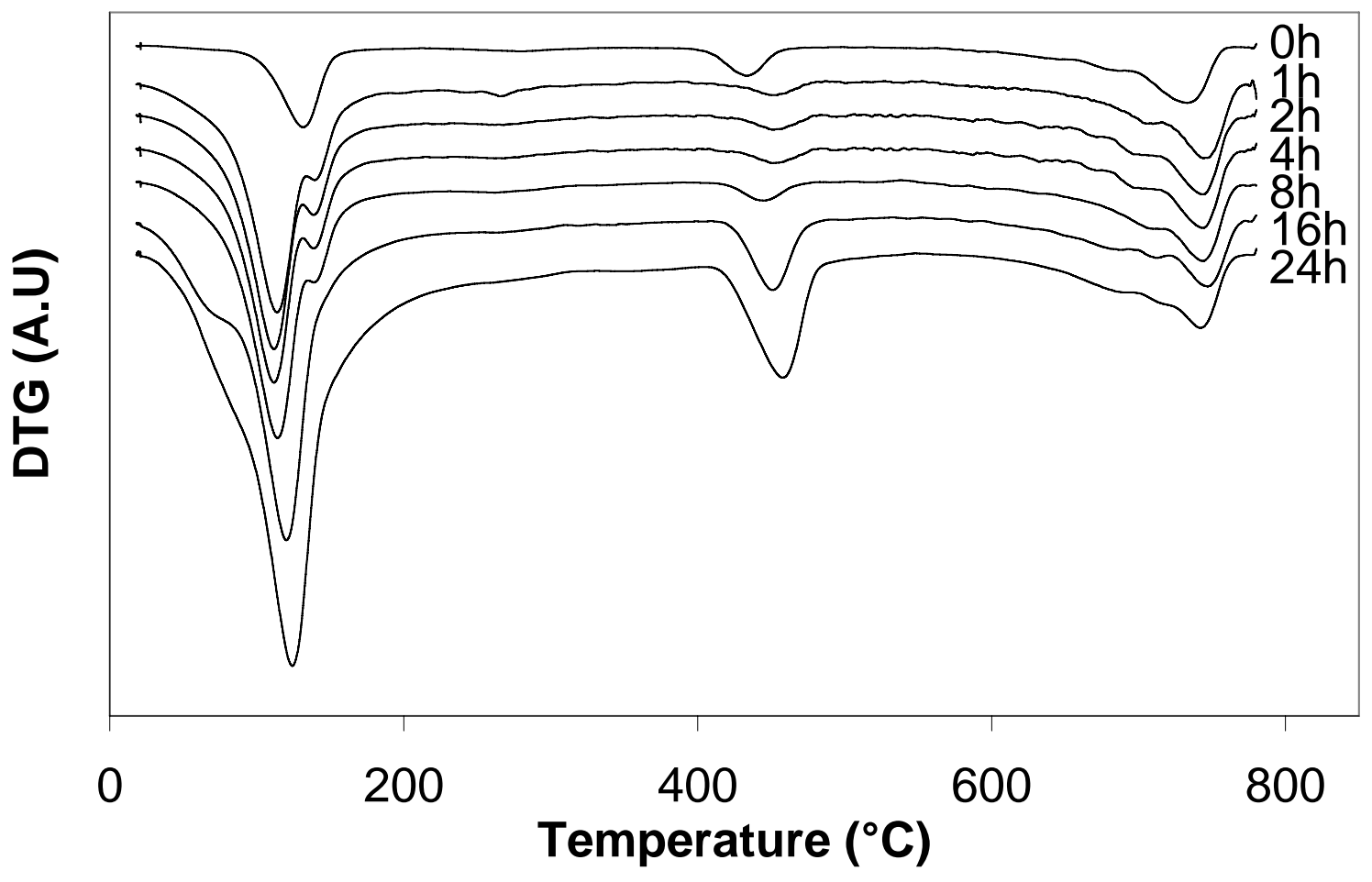


Fig 1c DTG curves of $\mathrm{C}_{1}+\mathrm{YD}$

A.Peschard, A.Govin, P.Grosseau, B.Guilhot, R.Guyonnet 
Fig 2

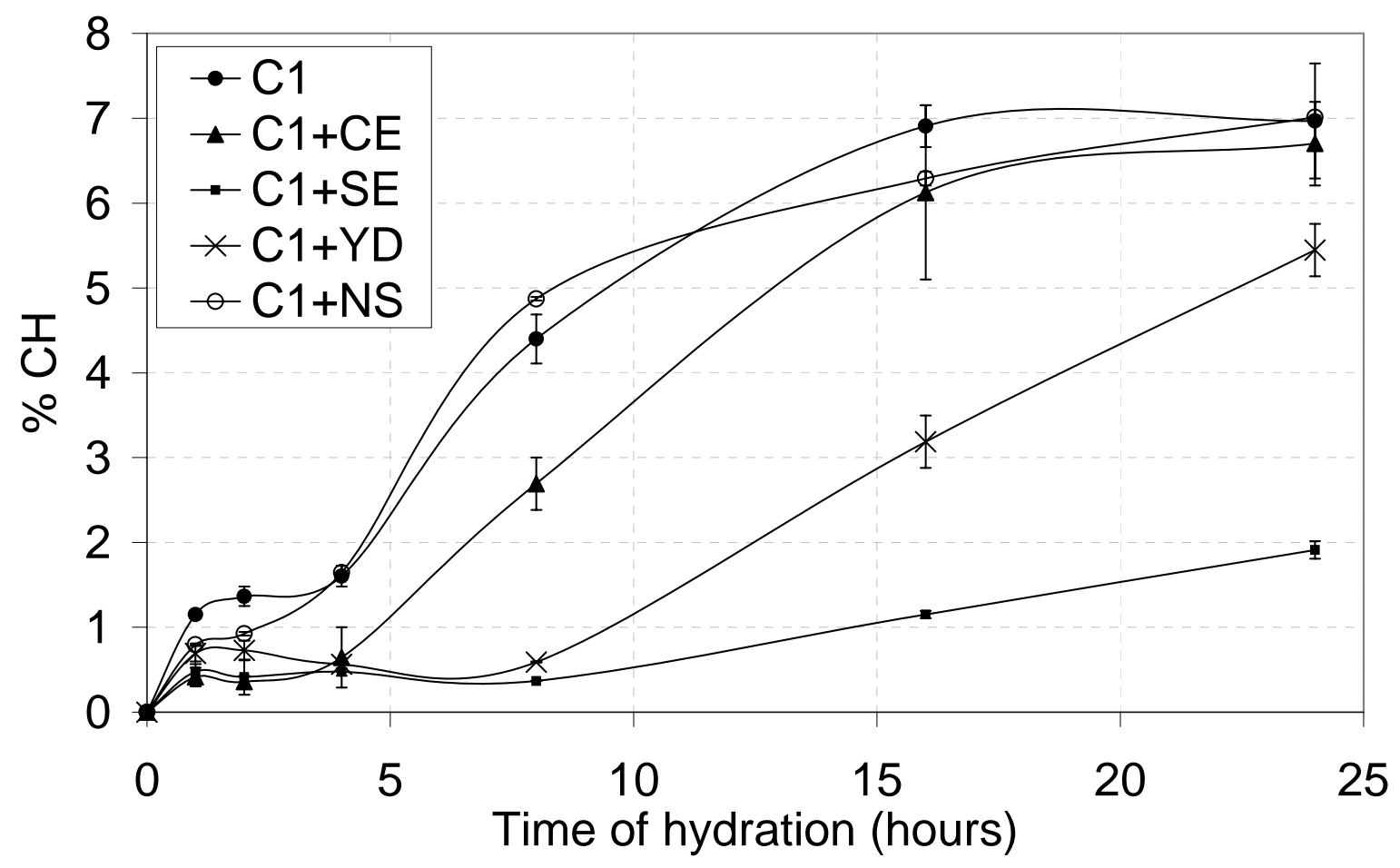


Fig 2 Evolution of portlandite content in admixed cement pastes

A.Peschard, A.Govin*, P.Grosseau, B.Guilhot, R.Guyonnet 
Fig 3

Kubelka-Munk

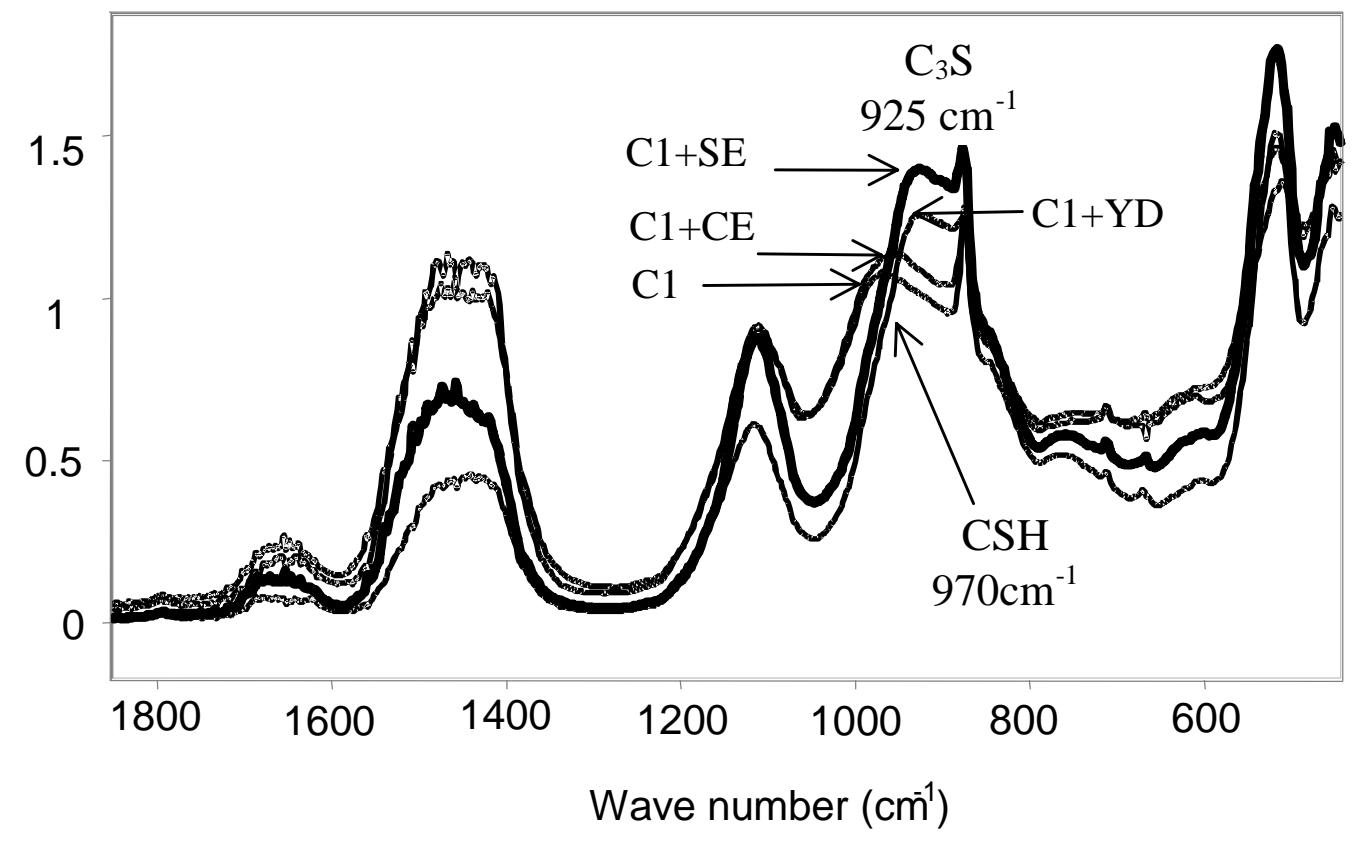


Fig 3 FTIR spectra of hydrated admixed cements.

A.Peschard, A.Govin, P.Grosseau, B.Guilhot, R.Guyonnet 
Table 4

\begin{tabular}{ccccc}
\hline Formula & $\mathrm{t}_{1}$ (hours) & $\mathrm{t}_{2}$ (hours) & $\mathrm{t}_{3}$ (hours) & $\mathrm{Q}_{24 \mathrm{~h}}(\mathrm{~J} / \mathrm{g})$ \\
\hline $\mathrm{C}_{1}$ & $2.4 \pm 0.3$ & $7.2 \pm 0.3$ & $11.2 \pm 0.6$ & $99 \pm 5$ \\
$\mathrm{C}_{1}+0.5 \% \mathrm{SE}$ & $2.2 \pm 1.5$ & $8.2 \pm 2.1$ & $14.5 \pm 4.1$ & $60 \pm 8$ \\
$\mathrm{C}_{1}+1.2 \% \mathrm{SE}$ & $3 \pm 0.2$ & $7.8 \pm 0.4$ & - & $45 \pm 5$ \\
$\mathrm{C}_{1}+1.5 \% \mathrm{SE}$ & $3 \pm 0.2$ & $7.9 \pm 0.3$ & - & $28 \pm 5$ \\
$\mathrm{C}_{1}+2 \% \mathrm{SE}$ & $3.8 \pm 0.3$ & $7.9 \pm 0.4$ & - & $8 \pm 1$ \\
$\mathrm{C}_{1}+0.1 \%$ YD & $2.2 \pm 0.2$ & $8.0 \pm 0.3$ & $12.2 \pm 0.5$ & $78 \pm 5$ \\
$\mathrm{C}_{1}+0.3 \%$ YD & $4.6 \pm 0.3$ & $15.0 \pm 0.5$ & - & $48 \pm 5$ \\
$\mathrm{C}_{1}+0.4 \%$ YD & $7.2 \pm 0.3$ & $16.4 \pm 0.8$ & - & $37 \pm 4$ \\
$\mathrm{C}_{1}+0.5 \%$ YD & $7.9 \pm 0.4$ & $18.2 \pm 1.1$ & - & $9 \pm 1$ \\
\hline
\end{tabular}


Table 4 Times and heat released in 24 hours for increasing concentration of SE and YD.

A.Peschard, A.Govin*, P.Grosseau, B.Guilhot, R.Guyonnet 
Fig 4a

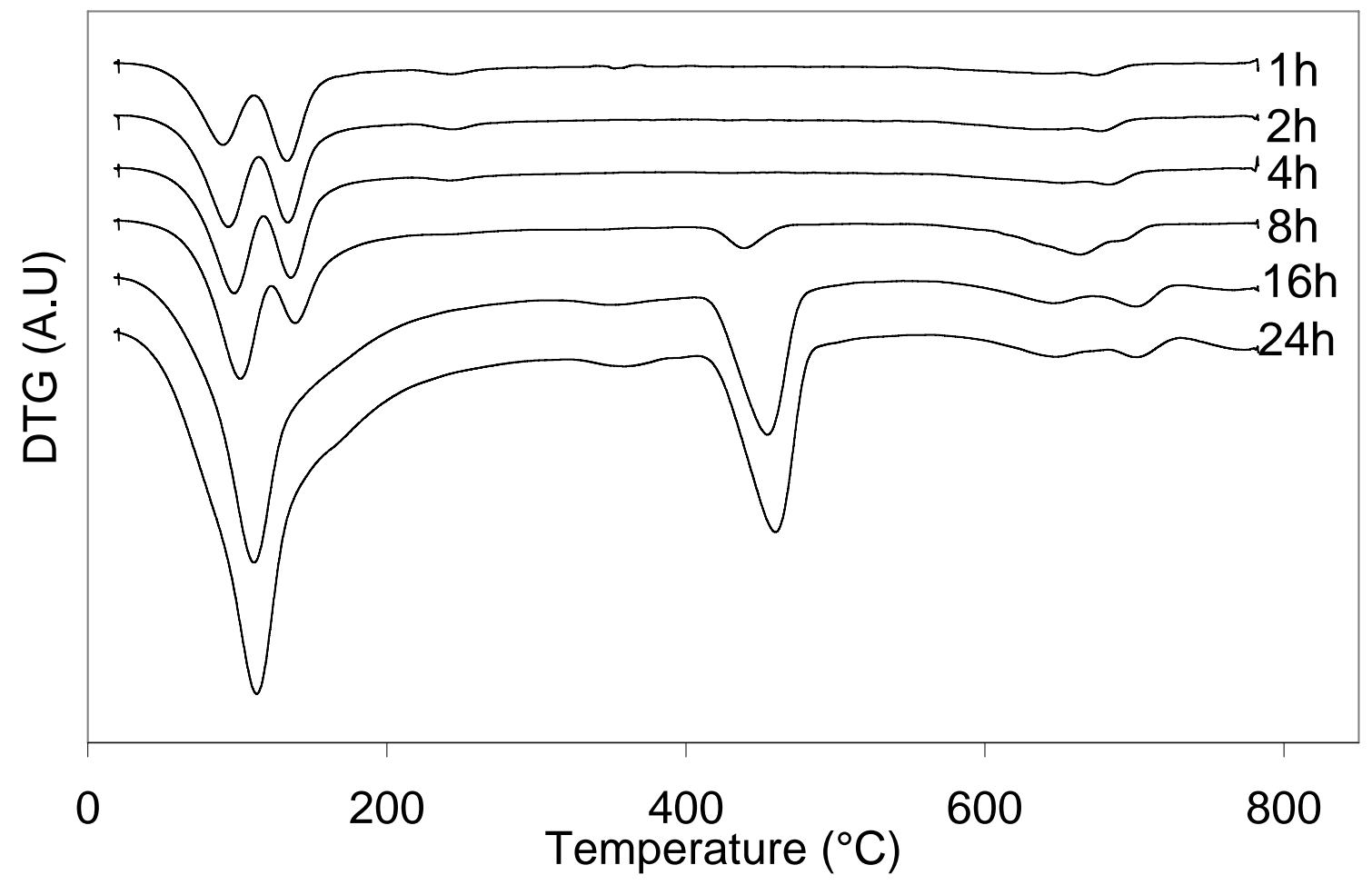


Fig 4a DTG curves of $\mathrm{C}_{2}$

A.Peschard, A.Govin, P.Grosseau, B.Guilhot, R.Guyonnet 
Fig 4b

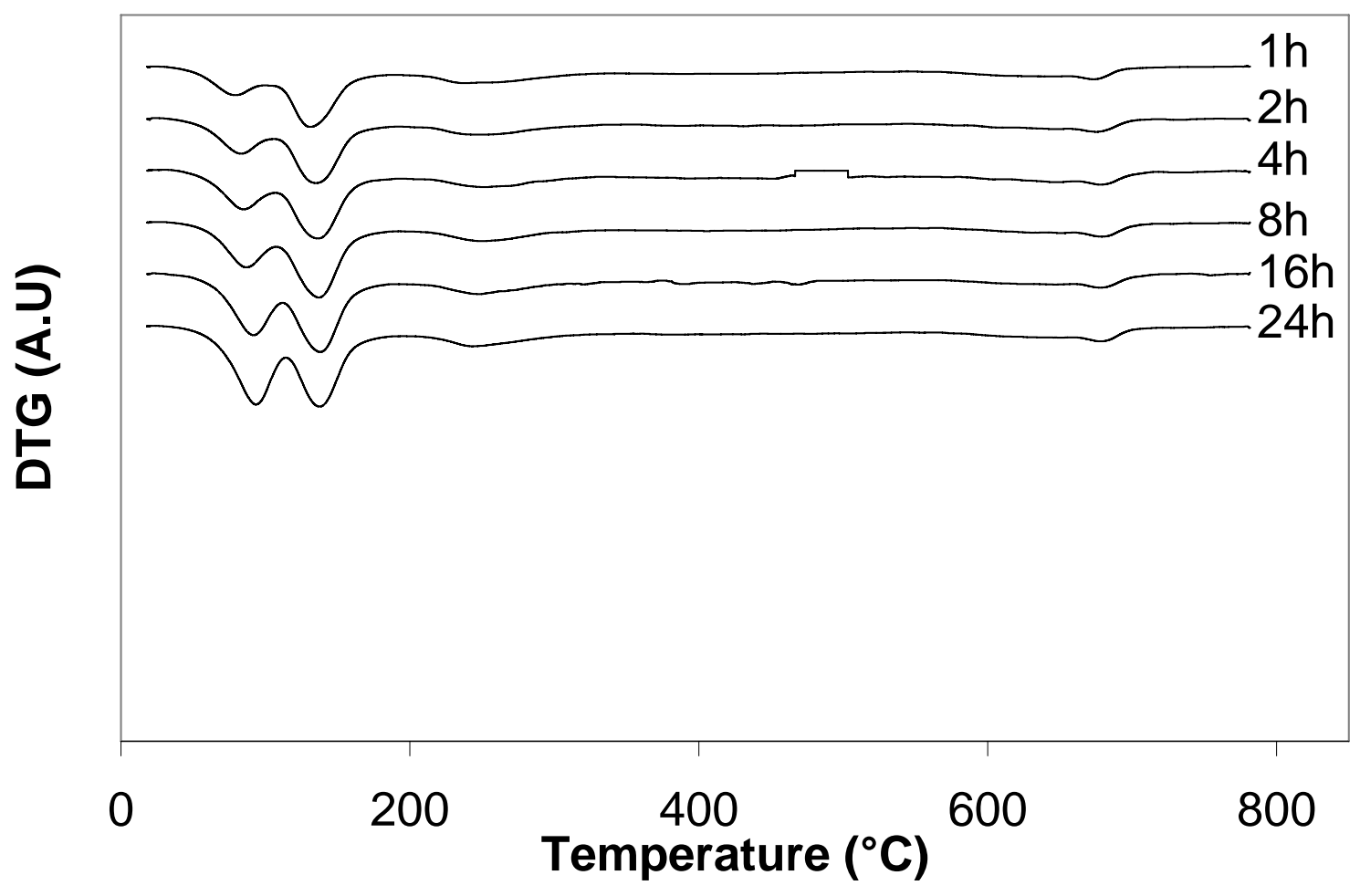


Fig 4b DTG curves of $\mathrm{C}_{2}+\mathrm{YD}$

A.Peschard, A.Govin, P.Grosseau, B.Guilhot, R.Guyonnet 
Fig 5

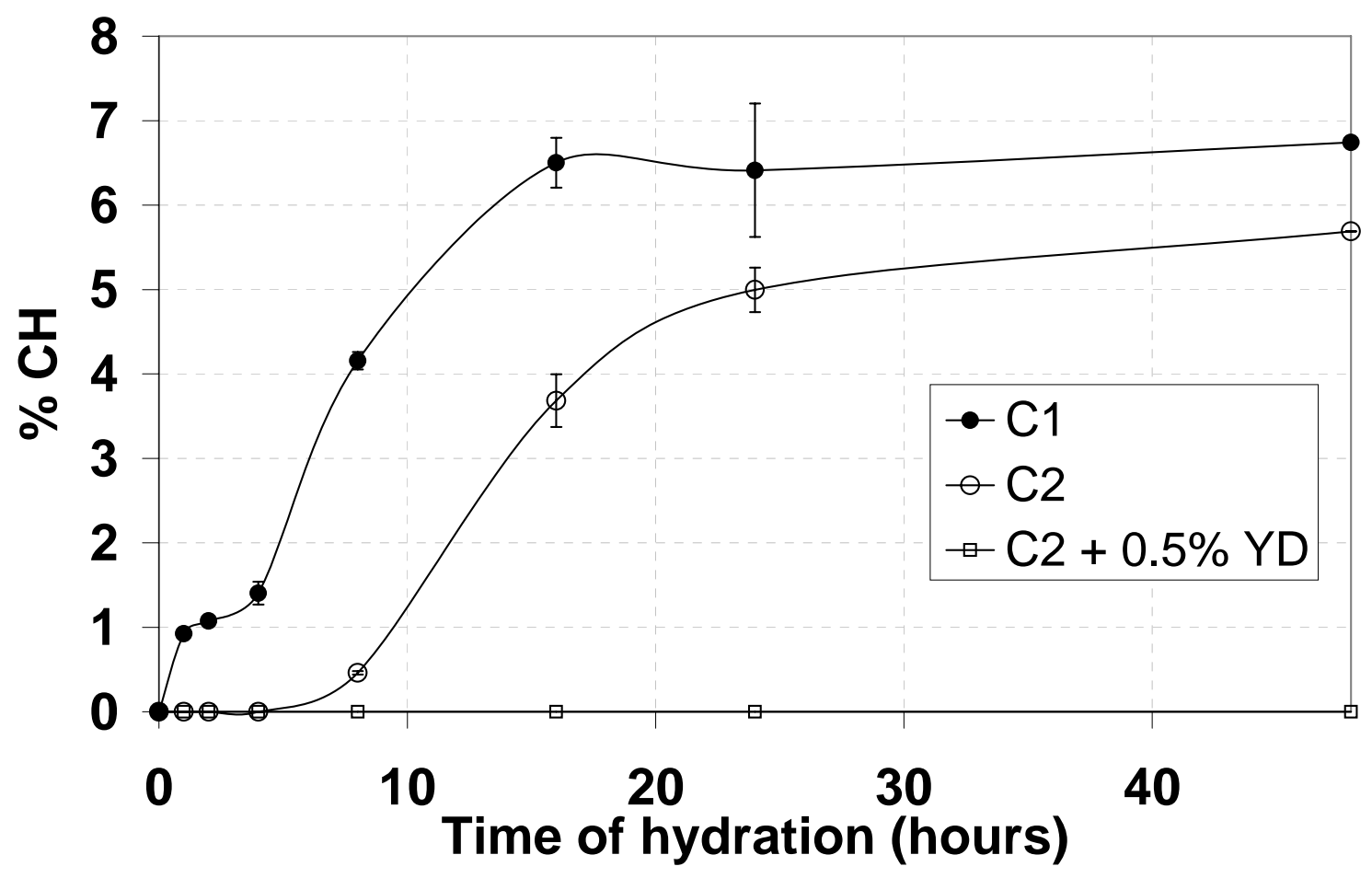


Fig 5 Effect of cement composition on the retarding ability of YD.

A.Peschard, A.Govin, P.Grosseau, B.Guilhot, R.Guyonnet 
Fig 6

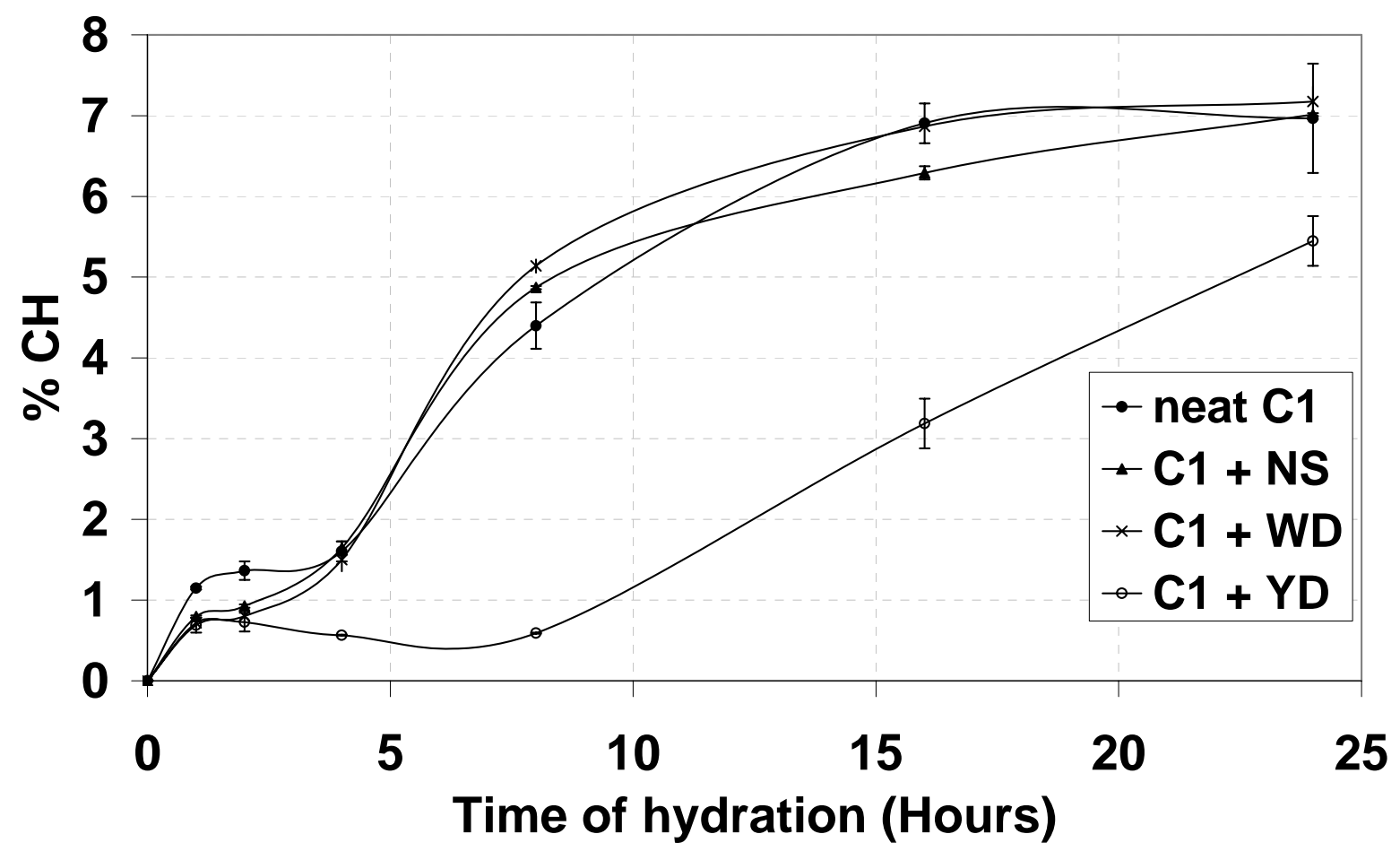


Fig 6 Effect of starch dextrinization on the evolution of $\mathrm{CH}$ formation in $\mathrm{C}_{1}$.

A.Peschard, A.Govin*, P.Grosseau, B.Guilhot, R.Guyonnet 


\section{Captions}

Table 1 Chemical composition of cement and potential phases by Bogue approximation. Table 2 Properties of polysaccharides.

Table 3 Times and heat released in 24 hours as a function of polysaccharide added.

Fig 1 DTG curves of a $C_{1}, b_{1} C_{1}+S E$, c $C_{1}+Y D$.

Fig 2 Evolution of portlandite content in admixed cement pastes

Fig 3 FTIR spectra of hydrated admixed cements.

Table 4 Times and heat released in 24 hours for increasing concentration of SE and YD.

Fig 4 DTG curves of a $\mathrm{C}_{2}$, b $\mathrm{C}_{2}+\mathrm{YD}$.

Fig 5 Effect of cement composition on the retarding ability of YD.

Fig 6 Effect of starch dextrinization on the evolution of $\mathrm{CH}$ formation in $\mathrm{C}_{1}$. 